\title{
A Quantitative Approach of the Interaction between Metal Triflates and Organic Ligands Using Electrospray Mass Spectrometry
}

\author{
Jean-François Gal, Claudio lacobucci, llaria Monfardini, Lionel Massi, Elisabet Duñach, \\ Sandra Olivero
}

Institut de Chimie de Nice, Université de Nice-Sophia Antipolis, CNRS-UMR 7272, Parc Valrose, 06108 Nice Cedex 2 , France

\begin{abstract}
The interaction between two Lewis "superacid" catalysts $\mathrm{Zn}(\mathrm{OTf})_{2}$ and $\ln (\mathrm{OTf})_{3}$ and series of amide and phosphate ligands is quantitatively characterized by electrospray ionization mass spectrometry (ESI-MS). A specific feature of the ESI-MS spectra of the mixture of metal triflates and Lewis bases is the formation of ionic adducts resulting from the displacement of one triflate anion by two neutral ligands. A ligand competition model is developed, which describes the relative intensities of the ionic adducts as a function of relative ligand concentrations. The relative affinities deduced from the ligand competition method are combined in an affinity scale for the metal triflate.
\end{abstract}

Key words: Lewis acids, Basicity, Metal triflates, Ligand competition, Catalysis

\section{Introduction}

$\mathrm{T}$ he experimental study of the structure and reactivity of gas-phase organometallic species by mass spectrometry (MS) has aroused a great interest with the advent of new mass analyzers and new ionization sources, especially those operating from the condensed phase [1-3]. Electrospray ionization (ESI) occupies a central position in the strategy for establishing a connection between the metal-containing ions existing in solution and those observed in the gas phase. A large part of these works aims at the search for mechanisms of the catalytic processes, and ESI has boosted the progress toward the characterization of elementary steps associated with organometallic catalysis, see for example [47]. In this communication, we propose an ESI-MS method for establishing quantitatively the relative affinity of organic ligands for the metal centers in triflate salts.

Electronic supplementary material The online version of this article (doi:10.1007/s13361-012-0484-x) contains supplementary material, which is available to authorized users.

Correspondence to: Jean-François Gal; e-mail: gal@unice.fr
Metal trifluoromethanesulfonates $\mathrm{M}(\mathrm{OTf})_{\mathrm{n}}$ (or triflates, $\mathrm{Tf}=\mathrm{CF}_{3} \mathrm{SO}_{2}$ ) behave as strong Lewis acids, and are occasionally called "Lewis superacids." Their powerful catalytic properties are exploited in many synthetic processes $[8,9]$, and their rational use will definitely benefit from a better understanding of their coordination ability. We recently established an ESI method for obtaining distinctive mass spectra of a series of metal triflates and triflimides $\mathrm{M}\left(\mathrm{NTf}_{2}\right)_{\mathrm{n}}$ [10]. By adding strongly basic ligands to these salts in nitromethane, we observed an efficient generation of positive ions corresponding mostly to the displacement of one anion $\left(\mathrm{OTf}^{-}\right.$or $\left.\mathrm{NTf}_{2}^{-}\right)$by two neutral ligands, leading to the characteristic singly charged ions $\left[\mathrm{M}^{\mathrm{n}+}\left(\mathrm{OTf}^{2}\right)_{\mathrm{n}-1}(\mathrm{~L})_{2}\right]$ or $\left[\mathrm{M}^{\mathrm{n}+}\left(\mathrm{NTf}_{2}{ }^{-}\right)_{\mathrm{n}-1}(\mathrm{~L})_{2}\right]$. The solvent nitromethane proved essential as ESI medium, giving useful and clean mass spectra. When two different ligands $\mathrm{A}$ and $\mathrm{B}$ were added to triflates, three species were formed: $\left[\mathrm{M}^{\mathrm{n}+}\left(\mathrm{OTf}^{-}\right)_{\mathrm{n}-1}(\mathrm{~A})_{2}\right]$, $\left[\mathrm{M}^{\mathrm{n}+}(\mathrm{OTf})_{\mathrm{n}-1}(\mathrm{~A})(\mathrm{B})\right]$, and $\left[\mathrm{M}^{\mathrm{n}+}(\mathrm{OTf})^{\mathrm{n}-1}(\mathrm{~B})_{2}\right]$. The relative intensities were interpreted as a ligand competition for the metal center [11]. We report here a quantitative interpretation of the concentration effect on the relative intensities of these three ions. 


\section{Experimental}

Experiments were performed on a quadrupole ion trap instrument. (LCQ Deca; Thermo Fisher Scientific, Courtaboeuf, France, Xcalibur software). The basic ESI conditions were: flow rate $3 \mu \mathrm{L} / \mathrm{min}$; ESI voltage: $3.1 \mathrm{kV}$; capillary temperature: $200{ }^{\circ} \mathrm{C}$; drying and nebulizer gas: nitrogen; $\mathrm{m} / \mathrm{z}$ range 50-2000. Organic ligands solutions were prepared from materials of commercial origin (Sigma-Aldrich-Fluka, Saint Quentin-Fallavier, France) used without further purification. Stock solutions of ligands and metal triflate at $310^{-3} \mathrm{molL}^{-1}$ in nitromethane were mixed to provide a final solution in the adequate concentration ratio. Details of the experimental procedure are available as Supporting Information (SI).

\section{Results and Discussion}

We address here the problem of extracting quantitative information from the ESI spectra of metal triflate/ligands mixtures. The representative cases of interaction between two metal triflates (zinc(II) and indium(III)) and two series of organic ligands (six amides and four phosphates) were examined. In our approach, it is assumed that neutral ligands $\mathrm{A}$ and $\mathrm{B}$ displace totally and rapidly one triflate anion by fixation of two molecules, either $2 \mathrm{~A}, 2 \mathrm{~B}$ or $(\mathrm{A}+\mathrm{B})$, on the metal center of the triflate salts $\mathrm{M}(\mathrm{OTf})_{\mathrm{n}}(n=2,3)$, Equations (1), (2), (3):

$$
\begin{aligned}
& \mathrm{M}^{\mathrm{n}+}\left(\mathrm{OTf}^{-}\right)_{\mathrm{n}}+2 \mathrm{~A} \rightarrow\left[\mathrm{M}^{\mathrm{n}+}\left(\mathrm{OTf}^{-}\right)_{\mathrm{n}-1}(\mathrm{~A})_{2}\right]+\mathrm{OTf}^{-} \\
& \mathrm{M}^{\mathrm{n}+}\left(\mathrm{OTf}^{-}\right)_{\mathrm{n}}+2 \mathrm{~B} \rightarrow\left[\mathrm{M}^{\mathrm{n}+}\left(\mathrm{OTf}^{-}\right)_{\mathrm{n}-1}(\mathrm{~B})_{2}\right]+\mathrm{OTf}^{-} \\
& \mathrm{M}^{\mathrm{n}+}\left(\mathrm{OTf}^{-}\right)_{\mathrm{n}}+\mathrm{A}+\mathrm{B} \rightarrow\left[\mathrm{M}^{\mathrm{n}+}\left(\mathrm{OTf}^{-}\right)_{\mathrm{n}-1}(\mathrm{AB})\right]+\mathrm{OTf}^{-}
\end{aligned}
$$

When ligands $\mathrm{A}$ and $\mathrm{B}$ are of comparable affinity for the metal center, two simultaneous equilibriums between the three charged species may be reached, Equations (4),(5). By combining these equations, a formal double exchange equilibrium (6) may be written:

$$
\begin{aligned}
& {\left[\mathrm{M}^{\mathrm{n}+}\left(\mathrm{OTf}^{-}\right)_{\mathrm{n}-1}(\mathrm{~A})_{2}\right]+\mathrm{B} \leftrightarrows\left[\mathrm{M}^{\mathrm{n}+}\left(\mathrm{OTf}^{-}\right)_{\mathrm{n}-1}(\mathrm{AB})\right]+\mathrm{A}} \\
& {\left[\mathrm{M}^{\mathrm{n}+}\left(\mathrm{OTf}^{-}\right)_{\mathrm{n}-1}(\mathrm{AB})\right]+\mathrm{B} \leftrightarrows\left[\mathrm{M}^{\mathrm{n}+}\left(\mathrm{OTf}^{-}\right)_{\mathrm{n}-1}(\mathrm{~B})_{2}\right]+\mathrm{A}} \\
& {\left[\mathrm{M}^{\mathrm{n}+}\left(\mathrm{OTf}^{-}\right)_{\mathrm{n}-1}(\mathrm{~A})_{2}\right]+2 \mathrm{~B} \leftrightarrows\left[\mathrm{M}^{\mathrm{n}+}\left(\mathrm{OTf}^{-}\right)_{\mathrm{n}-1}(\mathrm{~B})_{2}\right]+2 \mathrm{~A}}
\end{aligned}
$$

According to Trage et al. [12], a concentration ratio 1:2:1 for the three ions $\left[\mathrm{M}(\mathrm{A})_{2}(\mathrm{OTf})_{\mathrm{n}-1}\right],\left[\mathrm{M}(\mathrm{A})(\mathrm{B})(\mathrm{OTf})_{\mathrm{n}-1}\right]$ and $\left[\mathrm{M}(\mathrm{B})_{2}(\mathrm{OTf})_{\mathrm{n}-1}\right]$ is expected when ligands $\mathrm{A}$ and $\mathrm{B}$ have the same affinity for the metal center and are at the same concentration. Assuming proportionality between initial ion concentrations in solution and ion intensities after transfer in the gas phase, 1:2:1 relative intensities of the three ions should be observed in the mass spectrum, as represented schematically in the upper spectrum of Figure 1. Experimentally, such triplets are indeed observed [11], as shown in the experimental spectra

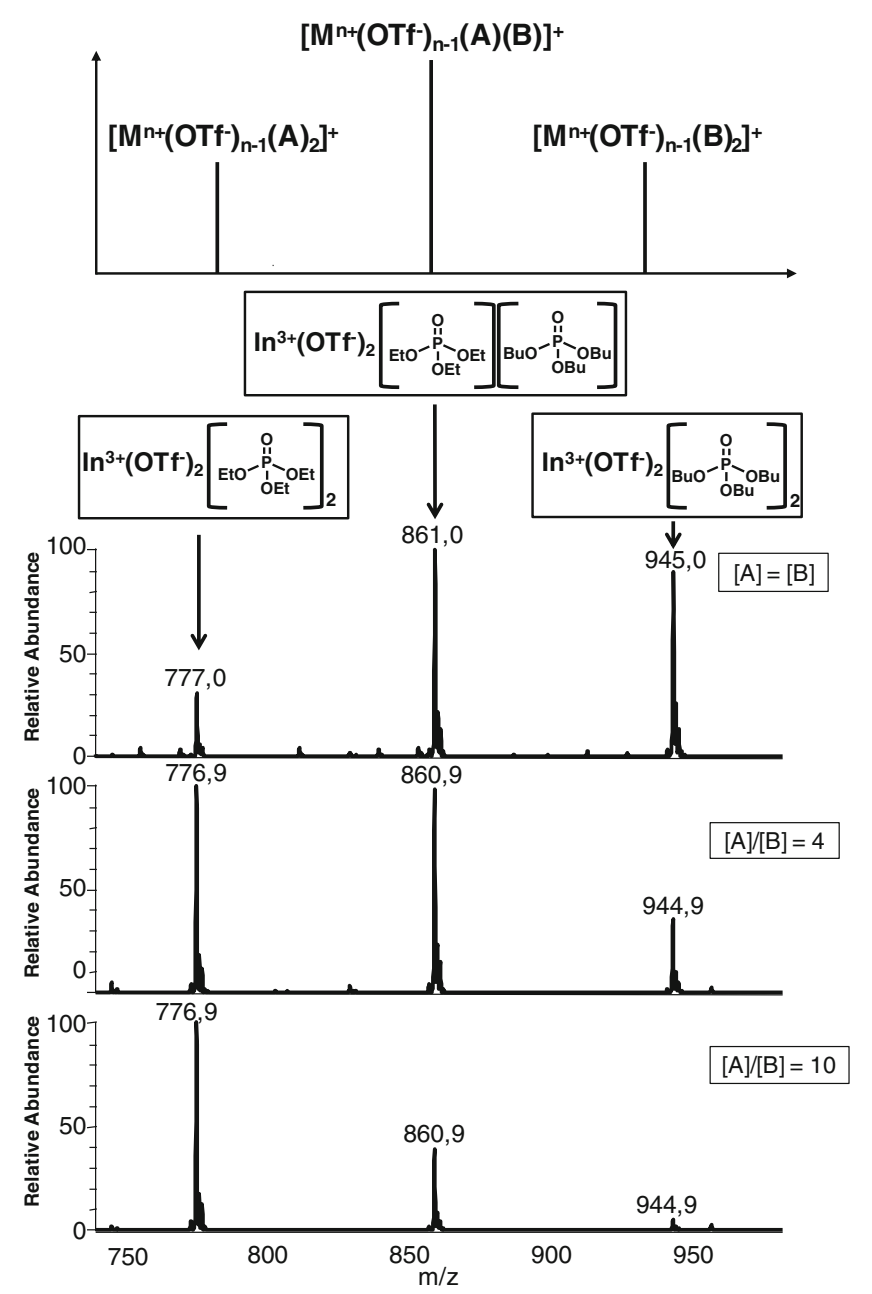

Figure 1. ESI spectrum of a mixture of indium triflate, triethylphosphate (A) and tri- $n$-butylphosphate (B) in $\mathrm{CH}_{3} \mathrm{NO}_{2}$ at three different concentration ratios. The bar spectrum above corresponds to the case of two ligands of equal affinities for the metal center and of equal concentrations

in Figure 1, obtained with indium triflate reacted with triethylphosphate (A) and tri- $n$-butylphosphate (B). The spectrum with equal concentrations of neutral ligands $[\mathrm{A}]=[\mathrm{B}]$ shows this triplet, with an enhanced intensity in favor of the later ligand. As expected, when $[\mathrm{A}]$ is increased the relative intensities of the adducts containing A increase.

The quantitative interpretation of the relation between concentrations $[\mathrm{A}]$ and $[\mathrm{B}]$ and the relative concentrations of $\left[\mathrm{M}^{\mathrm{n}+}(\mathrm{A})_{2}(\mathrm{OTf})_{\mathrm{n}-1}\right],\left[\mathrm{M}^{\mathrm{n}+}(\mathrm{B})_{2}(\mathrm{OTf})_{\mathrm{n}-1}\right]$ and $\left[\mathrm{M}^{\mathrm{n}+}(\mathrm{A})(\mathrm{B})(\mathrm{OTf})_{\mathrm{n}-1}\right]$ (and their relative intensities) is based on the probability of putting simultaneously two ligands on the metal center $\left(\mathrm{M}^{\mathrm{n}+}=\right.$ $\mathrm{Zn}^{2+}, \mathrm{In}^{3+}$ ), assuming no specific or variable interactions $\mathrm{A} / \mathrm{A}$, $\mathrm{B} / \mathrm{B}$ or $\mathrm{A} / \mathrm{B}$. A ligand competition model was devised, introducing in the bonding probabilities the relative affinity factor for the metal center $\alpha=\operatorname{Affinity}(\mathrm{A}) / \operatorname{Affinity}(\mathrm{B})$ and the concentration effect. Ion concentration ratios: $\alpha^{2}[\mathrm{~A}]^{2}: 2 \alpha[\mathrm{A}][\mathrm{B}]$ : $[\mathrm{B}]^{2}$, or $\alpha^{2}([\mathrm{~A}] /[\mathrm{B}])^{2}: 2 \alpha([\mathrm{A}] /[\mathrm{B}]): 1$ are derived from this model. A detailed account of the ligand competition model is given in SI. From these relations, it comes out that (i) the relative 
concentration (or intensity ratio) $Y_{\mathrm{M}(\mathrm{A}) 2 / \mathrm{M}(\mathrm{B}) 2}$ of the species $\left[\mathrm{M}^{\mathrm{n}+}(\mathrm{A})_{2}(\mathrm{OTf})_{\mathrm{n}-1}\right]$ to $\left[\mathrm{M}^{\mathrm{n}+}(\mathrm{B})_{2}\left(\mathrm{OTf}^{\mathrm{B}}\right)_{\mathrm{n}-1}\right]$ varies as the square of the affinity ratio and the square of the concentration ratio, $Y_{\mathrm{M}(\mathrm{A}) 2 / \mathrm{M}(\mathrm{B}) 2}=\alpha^{2}([\mathrm{~A}] /[\mathrm{B}])^{2}$; (ii) the relative concentration $Z_{\mathrm{M}(\mathrm{A}) 2 / \mathrm{M}(\mathrm{A})(\mathrm{B})}$ of species $\left[\mathrm{M}^{\mathrm{n}+}(\mathrm{A})_{2}\left(\mathrm{OTf}^{2}\right)_{\mathrm{n}-1}\right]$ to $\left[\mathrm{M}^{\mathrm{n}+}(\mathrm{A})(\mathrm{B})(\mathrm{OTf})_{\mathrm{n}-1}\right]$ is directly proportional to the affinity ratio and to the concentration ratio, $Z_{\mathrm{M}(\mathrm{A}) 2 / \mathrm{M}(\mathrm{A})(\mathrm{B})}=1 / 2 \alpha[\mathrm{A}] /$ [B], and similarly $\mathrm{Z}_{\mathrm{M}(\mathrm{A})(\mathrm{B}) / \mathrm{M}(\mathrm{B}) 2}=2 \alpha[\mathrm{A}] /[\mathrm{B}]$ for the ratio of $\left[\mathrm{M}^{\mathrm{n}+}(\mathrm{A})(\mathrm{B})(\mathrm{OTf})_{\mathrm{n}-1}\right]$ to $\left[\mathrm{M}^{\mathrm{n}+}(\mathrm{B})_{2}(\mathrm{OTf})_{\mathrm{n}-1}\right]$. A series of relative affinity measurements was performed by increasing the concentration of the ligand of weakest basicity, using concentration ratios of 1,2, 4, 7, and 10 . The intensity ratios of the ion triplet in the ESI mass spectra were treated by linear regression analysis by plotting $Y_{\mathrm{M}(\mathrm{A}) 2 / \mathrm{M}(\mathrm{B}) 2}=\alpha^{2}([\mathrm{~A}] /[\mathrm{B}])^{2}$ (linearized) and $Z_{\mathrm{M}(\mathrm{A}) 2 / \mathrm{M}(\mathrm{A})(\mathrm{B})}=1 / 2 \alpha[\mathrm{A}] /[\mathrm{B}]$. The relative affinities $\alpha$ were extracted from the slopes of the linear relations. The $\alpha$ values obtained from such plots are tabulated in the SI. The values of the two affinity ratios resulting from the two plots are quite close. This is a posteriori a verification that the affinity is nearly independent of the other ligand already bound to the metal.

Considering the analogy of the affinity with an equilibrium constant (see SI), $\alpha$ values were converted in logarithmic values (which are additive) and combined for obtaining relative affinity scales for the amide and phosphate series, relative to zinc and indium triflates. The affinity scales for the two ligand series reacting with $\mathrm{Zn}(\mathrm{OTf})_{2}$ and $\operatorname{In}(\mathrm{OTf})_{3}$ are reported in Table 1 . The amide and phosphate scales are presently not quantitatively connected, but preliminary measurements indicate that phosphates are stronger bases than amides, and that the strongest amides present affinities close to those of the weakest phosphates. The observed ions are initially in solution, and their quantitation by ESI-MS may introduce a bias in the concentration ratio. As suggested by the conclusion of the Di Marco and Bombi review [13] on metal/ligand equilibria, the ionization efficiencies can be reasonably assumed to be very similar for ions of general formula $\left[\mathrm{M}(\mathrm{A})_{2}(\mathrm{OTf})_{\mathrm{n}-1}\right],\left[\mathrm{M}(\mathrm{A})(\mathrm{B})(\mathrm{OTf})_{\mathrm{n}-1}\right]$ and $\left[\mathrm{M}(\mathrm{B})_{2}(\mathrm{OTf})_{\mathrm{n}-1}\right]$. In another recent approach of ESI ionization efficiency, Traldi and coworkers stated that ion mobility in the liquid phase, which depends essentially on the analyte dimension and charge state, is a

Table 1. Logarithmic Scales of Relative Affinities Obtained by Stepwise Addition $(\Sigma \ln \alpha)$; Corresponding Gibbs Energy Values $\left(\mathrm{kJmol}^{-1}\right.$, See Text) are Given in Parenthesis (Uncertainties not Included for Clarity; Available in SI)

\begin{tabular}{lll}
\hline Ligands & Zinc triflate & Indium triflate \\
\hline Amides & & \\
4-Methylbenzamide & $3.97(9.9)$ & $3.42(8.5)$ \\
Benzamide & $3.05(7.6)$ & $2.10(5.2)$ \\
$N, N$-Diethylacetamide & $2.57(6.4)$ & $2.39(6.0)$ \\
$N, N$-Dimethypropanamide & $1.49(3.7)$ & $1.23(3.1)$ \\
$N, N$-Dimethylacetamide & $1.18(2.9)$ & $1.29(3.2)$ \\
$\quad N$-Methylacetamide & $0^{\mathrm{a}}$ & $0^{\mathrm{a}}$ \\
$\begin{array}{l}\text { Phosphates } \\
\text { Tributylphosphate }\end{array}$ & $4.12(10.3)$ & $4.79(11.9)$ \\
Triethylphosphate & $2.88(7.2)$ & $4.12(10.3)$ \\
Trimethylphosphate & $0^{\mathrm{a}}$ & $2.24(5.6)$ \\
Triphenylphosphate & $1.48(3.7)$ & $0^{\mathrm{a}}$ \\
\end{tabular}

${ }^{\mathrm{a}}$ The beginning of the relative affinity scale was assigned to the ligand of weakest basicity. critical parameter [14]. Considering that singly-charged ions of similar shape and size are observed, ion mobility should not produce a significant discrimination between ESI intensities within the ion triplet used for affinity quantitation. Even if the kinetics of exchange are close to the diffusion limit, it is unlikely that the initial equilibrium will shift on the time-scale of the ESI droplets formation, transport and ion desolvation [15], the duration of these processes being of the order of the millisecond [14-16].

Finally, the successful application of our model in describing the intensities of the $\left[\mathrm{M}(\mathrm{A})_{2}(\mathrm{OTf})_{\mathrm{n}-1}\right],\left[\mathrm{M}(\mathrm{A})(\mathrm{B})(\mathrm{OTf})_{\mathrm{n}-1}\right]$ and $\left[\mathrm{M}(\mathrm{B})_{2}(\mathrm{OTf})_{\mathrm{n}-1}\right]$ ions as a function of the relative concentrations of the ligands can be regarded as an indirect proof that intensities in the ESI spectra actually reproduce the solution content.

The relative affinity parameter $\alpha$, which was derived from our model, appears as a kind of equilibrium constant. The associated thermodynamic values are only approximate because the solution is at room temperature, the later being not strictly controlled. The question of the "temperature" (or internal energy distribution) of completely desolvated ions has been addressed in several studies, see for example the references cited by [17]. Ion excitation in ESI is essentially produced by collisions of the charged droplets and the resulting ions with the drying gas molecules during the desolvation step (including the passage through a heated capillary in our instrument), especially during their acceleration period before entering the mass analyzer, but these considerations are clearly not relevant to the temperature of the initial liquid phase. If we admit that the kinetic of exchange reactions in Equations $(4,5)$ is sufficiently slow, i.e. "frozen" on the millisecond life-time of the droplets and the resultant ions, the conclusion is that we actually observe the ion composition at the temperature of the solution.

From the equivalence between $\alpha$ and equilibrium constants, an order of magnitude of the corresponding relative Gibbs energies $\left(-R T \sum \ln \alpha\right)$ for the interaction between each family of ligands and the two Lewis acid can be estimated in the range $8-12 \mathrm{kJmol}^{-1}$. The zinc and indium triflates give almost the same ranges and affinity orders for amides and phosphates. This is likely the result of the similarity of the ion size (ionic radii) and metal-oxygen bond distances [18-20]. The magnitude of these substituent effects is comparable to what is observed for adduct formation with $\mathrm{Li}^{+}$in the gas phase and with $\mathrm{BF}_{3}$ in solution [21]. The $N$-methylation effect when going from $\mathrm{MeCONHMe}$ to $\mathrm{MeCONMe}_{2}$ causes an affinity increase of about $1.2 \mathrm{log}$ units (equivalent to $\sim 3 \mathrm{~kJ} \mathrm{~mol}^{-1}$ ) for zinc and indium triflate adducts (Table 1), to be compared to $5.7 \mathrm{~kJ} \mathrm{~mol}^{-1}$ for $\mathrm{Li}^{+}$cation basicity [21]. Gas-phase lithium cation basicity $\left(\mathrm{LiCB}=\right.$ Gibbs energy of dissociation of $\mathrm{Li}^{+} /$ligand adduct) is a useful parameter for comparison, because it is free from solvent and steric effects. The regular increase of $\mathrm{LiCB}$ as a function of alkyl size in alkylamides indicates the action of a stabilizing polarizability effect $[22,23]$, which may be attenuated by solvation in our cases.

Overall, there is no precise correlation between our affinity parameter and LiCB. The primary benzamides appear to be stronger ligands than the secondary and tertiary alkylamides. The relatively stronger affinity of primary amides toward $\mathrm{Zn}$ (II) and In(III), compared to $N$-alkylamides, may be due to the easier approach of the metal by the less sterically demanding primary 
amide function; note that the electron-donating effect of the 4methyl on benzamide gives the expected affinity increases. Zinc(II) and indium(III) metal centers of the ions examined in this work are, respectively, three- and four-coordinated. Consequently, only a limited repulsion between the ligands in the coordination sphere can be inferred, but the presence of the additional ligands in the case of the indium adducts may bring more inter-ligand repulsion. Comparison of the $\mathrm{Zn}$ (II) and In (III) scales reveals an inversion of the affinity order for the couple trimethylphosphate (TMP)-triphenylphosphate (TPP), attributable to a steric effect. The $(\mathrm{PhO})_{3} \mathrm{P}$ moiety in TPP is undoubtedly more sterically demanding than $(\mathrm{MeO})_{3} \mathrm{P}$ in TMP [24], and this effect dominates the indium adduct behavior in the phosphate series, although the affinity increase as a function of alkyl size indicates a stabilizing polarizability effect, as in the amide series. In the gas phase, the $\mathrm{LiCB}$ order is $(\mathrm{BuO})_{3} \mathrm{PO}$ (estimated) $>(\mathrm{PhO})_{3} \mathrm{PO} \geq(\mathrm{EtO})_{3} \mathrm{PO}>(\mathrm{MeO})_{3} \mathrm{PO}[21]$. As no steric effect is expected for $1: 1$ adducts of the $\mathrm{Li}^{+}$cation, the position of $(\mathrm{PhO})_{3} \mathrm{PO}$ in the metal triflate scales indicates a competition between the stronger electron-withdrawing effect of the phenoxy relative to the alkoxy groups [25, 26], and the larger polarizability of the phenyl relative to the smaller alkyls.

\section{Conclusions}

This communication presents a quantitative approach of the relative strength of interaction between different ligands and two metal triflates known for their catalytic activity. The displacement of one anion of the salt by two neutral ligands is observed by ESI-MS. When two different ligands are competing for the metal center, two simple relationships generate an affinity ratio which is an estimate of the relative affinity of the ligands for this metal center. The method appears to be applicable to a range of Lewis superacids $[10,11]$, as well as other ligands representative of reactive substrates, and expands the possibility of ESI-MS to solve solution chemistry problems [27]. Density functional theory calculations are currently carried out as an aid for the interpretation of structural effects on the Lewis acid/base interactions, and for the calibration of the affinity scales into energy scales.

\section{Acknowledgments}

Financial supports from Project ANR-07-CP2D-CASAL-0401 and the University of Nice-Sophia Antipolis (postdoctoral grant to I.M.) are gratefully acknowledged. The authors are grateful to F. Jaulin, Sanofi-Aventis, for giving two ion trap mass spectrometers to our facility.

\section{Supporting Information Available}

Contents: Detailed treatment of the ligand competition method, experimental procedures, tables of relative affinities, evaluated $\mathrm{Li}^{+}$basicities and additional references.

\section{References}

1. Henderson, W., McIndoe, J.S.: Mass Spectrometry of Inorganic, Coordination and Organometallic Compounds, Chap 3-7. Wiley, Chichester, UK (2005)

2. Waters, T., Wang, X.B., Wang, L.S.: Electrospray ionization photoelectron spectroscopy: probing the electronic structure of inorganic metal complexes in the gas-phase. Coord. Chem. Rev. 251, 474-491 (2007)

3. Santos, L.S. (ed.): Reactive Intermediates: MS Investigations in Solution. VCH, Weinheim (2010)

4. Baumgarten, S., Lesage, D., Gandon, V., Goddard, J.-P., Malacria, M., Tabet, J.-C., Gimbert, Y., Fensterbank, L.: The role of water in platinumcatalyzed cycloisomerization of 1,6-Enynes: A combined experimental and theoretical gas phase study. ChemCatChem 1, 138-143 (2009)

5. Beierlein, C.H., Breit, B., Paz-Schmidt, R.A., Plattner, D.A.: Online monitoring of hydroformylation intermediates by ESI-MS. Organometallics 29, 2521-2532 (2010)

6. Fedorov, A., Chen, P.: Mechanistic insights from the gas-phase reactivity of phosphorus-ylid-supported benzylidene gold complexes. Organometallics 29, 2994-3000 (2010)

7. Clodfelter, W.C., Wong, E.H., Hay, K.A., Gronert, S.: Gas-phase ligand binding to Jacobsen's manganese salen catalyst: Functional group and steric effects. Int. J. Mass Spectrom. 305, 40-44 (2011)

8. Antoniotti, S., Poulain-Martini, S., Duñach, E.: Electrophilic Functionalization of Non-Activated Olefins Catalyzed by Lewis Superacids. Synlett 2973-2988 (2010)

9. Prakash, G.K.S., Mathew, T., Olah, G.A.: Gallium(III) triflate: An efficient and a sustainable Lewis acid catalyst for organic synthetic transformations. Acc. Chem. Res. 45, 565-577 (2012)

10. Monfardini, I., Massi, L., Trémel, P., Hauville, A., Olivero, S., Duñach, E., Gal, J.-F.: Mass spectrometric characterization of metal triflates and triflimides (Lewis superacid catalysts) by electrospray ionization and tandem mass spectrometry. Rapid Commun. Mass Spectrom. 24, 2611-2619 (2010)

11. Monfardini, I., Massi, L., Duñach, E., Olivero, S., Gal, J.-F.: Relative basicities toward metal triflates Lewis acids by electrospray mass spectrometry. Chem. Commun. 46, 8472-8474 (2010)

12. Trage, C., Schröder, D., Schwarz, H.: Coordination of Iron(III) cations to $\beta$ keto esters as studied by electrospray mass spectrometry: Implications for iron-catalyzed Michael addition reactions. Chem. Eur. J. 11, 619-627 (2005)

13. Di Marco, V.B., Bombi, G.G.: Electrospray mass spectrometry (ESIMS) in the Study of metal-ligand solution equilibria. Mass Spectrom. Rev. 25, 347-379 (2006)

14. Crotti, S., Seraglia, R., Traldi, P.: Some thoughts on electrospray ionization mechanisms. Eur. J. Mass Spectrom. 17, 85-99 (2011)

15. Peschke, M., Verkerk, U.H., Kebarle, P.: Features of the ESI mechanism that affect the observation of multiply charged noncovalent protein complexes and the determination of the association constant by the titration method. J. Am. Soc. Mass Spectrom. 15, 1424-1434 (2004)

16. Mirza, U.A., Chait, B.T.: Do proteins denature during droplet evolution in electrospray ionization? Int. J. Mass Spectrom. Ion Processes 162, 173-181 (1997)

17. Rondeau, D., Galland, N., Zins, E.-L., Pepe, C., Drahos, L., Vékey, K.: Non-thermal internal energy distribution of ions observed in an electrospray source interfaced with a sector mass spectrometer. J. Mass Spectrom. 46, 100-111 (2011)

18. Huheey, J.E., Keiter, E.A., Keiter, R.L.: Inorganic Chemistry. Principles of Structure and Reactivity, 4th edn, pp. 112-117. HarperCollins College Publishers, New York (1993)

19. Marcus, Y.: Ionic radii in aqueous solutions. Chem. Rev. 8, 1475-1498 (1988)

20. Inada, Y., Sugimoto, K., Ozutsumi, K., Funahashi, S.: Solvation structures of manganese(II), iron(II), cobalt(II), nickel(II), copper(II), zinc(II), cadmium(II), and indium(III) ions in 1,1,3,3-tetramethylurea as studied by EXAFS and electronic spectroscopy. Variation of Coordination Number. Inorg. Chem. 33, 1875-1880 (1994)

21. Laurence, C., Gal, J.-F.: Lewis Basicity and Affinity Scales: Data and Measurement. Wiley, Chichester, UK (2010)

22. Taft, R.W.: Protonic acidities and basicities in the gas phase and in solution: Substituent and solvent effects. Prog. Phys. Org. Chem. 14, 247-350 (1983)

23. Taft, R.W., Topsom, R.D.: The nature and analysis of substitutent electronic effects. Prog. Phys. Org. Chem. 16, 1-82 (1987)

24. Tolman, C.A.: Steric effects of phosphorus ligands in organometallic chemistry and homogeneous catalysis. Chem. Rev. 77, 313-348 (1977)

25. Mastryukova, T.A., Kabachnik, M.I.: Correlation constants in the chemistry of organophosphorus compounds. J. Org. Chem. 36, 1201-1205 (1971)

26. Hansch, C., Leo, A., Taft, R.W.: A survey of Hammett substituent constants and resonance and field parameters. Chem. Rev. 97, 165-195 (1991)

27. Schröder, D.: Ion clustering in electrospray mass spectrometry of brine and other electrolyte solutions. Phys. Chem. Chem. Phys. 14, 6382-6390 (2012) 